\title{
Perceptions of Hotel Employees on The Reduction of Disposable Toiletries: The Case of Guangzhou Hotels in China
}

\author{
Ding Ran \\ Centro Escolar University, Manila, Philippines
}

\begin{abstract}
Nowadays, the world has placed great importance to environmental problems and China has become increasingly concerned about environmental protection. Since September 1, 2019, all-star-rated hotels in Guangzhou had imposed restrictions on the use of disposable items. This paper sought to find out whether hotel employees' profile can affect their perceptions on the implementation of the reduced supply of toiletries and disposables among selected five-star hotels in Guangzhou, China. With the new regulations issued by the Guangzhou government, moreover, the concept of a green hotel, has led the researcher to investigate a range of issues as a result of these new regulations and related environmental awareness among hotel employees. The study employed descriptive-quantitative research using questionnaires answered by the 108 hotel employees. The results showed the profile of respondents did affect their perceptions, the researcher aimed to improve the attitude, awareness and readiness of the hotel employees on the reduction of disposable toiletries and gave suggestions on how to promote the green hotel in Guangzhou.
\end{abstract}

Keywords: Green Hotel, Domestic Waste Management, Star-Rated Hotels, Guangzhou, China

Corresponding author: Ding Ran; E-mail: 446247283@qq.com

DOI: https://doi.org/10.37227/ITHJ-2021-02-98

\section{Introduction}

For the hotel industry, to reduce or eliminate hazards to human health and environment, one of the ways is by reducing pollution at its source; improving resource efficiency and reducing or avoiding the generation and release of pollutants in the production, service and product use (China Hospitality Association, 2015). To accomplish this, Guangzhou had issued the "Special Action Plan for the Comprehensive Promotion and Reduction of Disposable in Star Hotels in Guangzhou" on September 1, 2019 which meant hotels cannot proactively provide disposable items, namely "six small pieces": toothbrush, hairbrush, bath brush, shoe brush, razor, and nail file, in the hotel guest rooms (Guangzhou Municipal Culture, Radio, Television and Tourism Bureau, 2019). There are $3,245,800$ hotel rooms in China, and at least 65 million disposable items were used and discarded at $50 \%$ occupancy rates (Hebei News, 2019). In this condition, the abolition of 
these "six small pieces" to reduce waste of resources will greatly contribute to the environmental protection which has both economic and social benefits. That is to say, it will not only solve the waste and pollution problem but also guide consumers to develop green consumption habits in long term.

"Green Hotel" is an environmental symbol widely used in the international hotel industry. From the dual purposes of strengthening environmental protection and improving the competitiveness of hotels, environmental management has been carried out since the 1980s and achieved remarkable results (Liu, 2008). Therefore, the hotel's environmental management has been put on the agenda, and the creation of the "Green Hotel" is an important link in environmental protection. Although China is a developing country, it has made remarkable achievements in the economic field and it feels a great responsibility to protect the environment. The protection of the environment should not solely rely on the Chinese government's efforts but all its people should work together for it.

By the end of 2018, the number of star-rated hotels had exceeded 10,500 in China. The ratios of these four grades were: Economy (two-star or below) $87.2 \%$, Midrange (three-star) 7.5\%, High-grade (four-star) 3.9\%, and Luxury (five-star) $1.4 \%$. From the industry composition, the hotel industry in terms of number of scale and grades, was to maintain a pyramid-shaped market structure. In 2019, the average occupancy rate of all the star-rated hotels was $57.43 \%$ (Ministry of Culture and Tourism of the People's Republic of China, 2019). China's hotel demand for middle and high-end grades have accelerated its concentration with demand structure change-driven industrial structure upgrading. At present, the supply of hotels in China is mainly concentrated in economy hotels. Driven by the rapid rise of the middle class and the constant upgrading of rational consumption, the demand has gradually shifted to medium-and high-end service hotels (CIIN, 2018).

As a place of high consumption, the hotel industry needs to take the environmental issues seriously. The hotel industry has occupied and expended a large number of natural resources, discharged a large number of waste materials which may have caused the deterioration of the ecology and the depletion of natural resources. Increasingly, with the booming development of the hotel industry, it has been facing more problems such as the environmental problems which it caused that has attracted people's attention. As the hotel industry gathers wealth, there is a serious waste of energy and resources, especially the use of disposable and water and electricity. It was once considered an advanced standard for hotels to equip themselves with disposable room amenities, but now it is a huge burden to the environment. According to the traditional service of the hotel, the disposable consumables such as toothpaste, toothbrush, comb, slippers, bath lotion, disposable towels, and other disposable cotton articles, which are provided free to the guests, has caused terrible waste and considerable environmental pollution (Li, 2013).

\section{Current Situation of Tourism in China}

\section{Literature Review}

In 2018, the number of domestic tourists was 5.539 billion in China which is an increase of 10.8 percent over the same period last year; the total number of inbound and outbound tourists was 291 million, an increase of 7.8 percent over the same period last year; and total tourism revenue was 5.97 trillion yuan, an increase of 10.5 percent over the same period last year. According to preliminary calculation, the overall contribution of tourism to GDP in China was 9.94 trillion yuan, accounting for $11.04 \%$ of the total GDP. 28.26 million people were directly 
employed in tourism, and 79.91 million were directly or indirectly employed, accounting for 10.29 percent of the total employed population (MCTPRC, 2019).

China's hotel industry is one of the three pillar industries of tourism, after its reform and opening-up, it has seen a rapid development. After so many years of development and change, it has become a modern enterprise where various economic subjects coexist (Chen, 2019). Therefore, China's tourism enterprises should minimize the consumption of resources and energy in their construction, development, and operation, provide green tourism products to their customers, and actively participate in the activities of environmental protection and tourism resources protection. The relationship between protection, development, and utilization should be well handled so as to achieve the "win-win" of economic and social benefits ( $\mathrm{Li}, 2007)$.

As of August 16, 2019, China has a total of 886 five-star hotels with 135 five-star hotels in Guangdong and 21 in Guangzhou (China Tourist Hotel Association, 2019). According to the Yangcheng Evening News (2019a), the starrated hotels need 1.27 million disposable items a day in Guangzhou.

\section{Impact of Policy in the Hotel Industry in China}

The basis of green hotel operation is a three-part balance of "profits, people, and planet" in which green hotels should be promoted in this condition (Wang, 2014). However, some hotel operators may think that environmental protection will harm their economic interests. Thus, companies do not voluntarily embrace standards that invite them to internalize environmental costs and risks (Zhang, Wu, Liu, \& Zhang, 2017). In addition to the financial implications of customer experience and Green Practices, the lack of government legislation and enforcement also hampers the development of green hotels, enterprises are profit-oriented, lack government supervision, enterprises will not take the initiative to shoulder social responsibility (King, et al., 2017). Therefore, the market needs government intervention.

The policy has a serious impact on Chinese enterprise. The development of hotel industry has gradually shown obvious structural differentiation characteristics. As a result of "three public" (refers to the consumption of the personnel of government departments due to the expenses of going abroad on business, the purchase and operation of business vehicles, and the expenses of official entertainment) restriction on consumption and the "eight rules"(one of them is about the hotel industry. The government has exercised diligence and thrift, strictly observed the relevant regulations on clean government, and strictly implemented the regulations on housing, vehicle equipment, and other work and living conditions), luxury hotels represented by five-star hotels, consumer demand has dropped sharply. In the meantime, due to high operating costs, high real estate investment and other factors, luxury hotel development speed and scale growth rate has been decreasing year after year (Chen, 2019).

The Ministry of Culture and Tourism of the People's Republic of China (MCTPRC), in its capacity as the government's administrative authority, promulgates national industry standards, sets administrative regulations and issues administrative documents to provincial tourism authorities, promoting the implementation of "Green Hotel". Under the current management system of China, this kind of way is the most effective, the impetus dynamics is also the biggest (Liu, 2008). Although the MCTPRC published the Industry Standard for green 
tourist hotels, and the gold and silver leaf rating criteria were refined and quantified, but in the actual implementation process, as it is only the industry standard, there is no law binding force, even if the hotel did not comply with regulations, will not be punished by law, so the regulatory effect is poor (Tang, 2018).

Despite the new regulation, there are still many problems to be explored. Legislative and enforcement deficiencies, and the lack of environmental awareness, are the current primary reason for the cancellation of the hotel disposable items and the new regulation is making up for the lack of law and changing people's mind. A lot of good sense of the formation, often do not rely on people's voluntary, but the need for external compulsion, such as legislation and law enforcement. Being bound and guided by laws and regulations for a long time, consciousness and behavior will naturally be standardized (Zhou, 2015). Zhao Guoxiong, vice president of the China Tourist Hotel Industry Association stated that it is necessary to phase out and reduce disposable hotel supplies, which will play a big role in environmental protection. But consumer habits may not change completely for a while, requiring a process of adaptation (Zheng, 2012).

\section{Environmental Protection Related Policy in China}

For a long time after the reform and opening-up, China followed the traditional industrial civilization development model of "mass production, mass consumption, and mass abandonment". This kind of model impels China to make remarkable achievements in economic and social development in only decades, but it also brings about critical problems of resources and the environment (China Association of Circular Economy, 2017).

At present, China's carbon dioxide emissions are the world's largest due to its rapid development period of industrialization and urbanization. Reducing carbon emissions and accelerating economic development are facing unprecedented pressure (Yang, 2013). The government has introduced environmental regulations that appear to be a constraint on hotels, but in reality, hotels do not emit significant pollutants, and those that impose fines and regulations on heavy polluters, the binding force to the hotel enterprise is relatively limited. The current environmental protection laws and regulations encourage the hotel enterprises to be more energy-saving and following proper environmental protection, so the improvement of the relevant environmental protection laws and regulations can actually better encourage the hotel to adopt environmental behavior (Lu, 2015). However, environmental infrastructure construction and environmental management are underdeveloped (Wang, 2013).

In 2005, the Chinese government promoted "building an environmentfriendly and resource-saving society" to a strategic height, to this end, the government has taken a number of measures. In accordance with the requirements of "The Plan for Further Strengthening the Classification of Domestic Waste in Key Industries", Guangzhou has issued the "Special Action Plan for the Comprehensive Promotion and Reduction of Disposable in Star Hotels in Guangzhou" on September 1, 2019 (GMCRTTB, 2019). The city's star hotels have promoted the work of reducing disposable special mobilization deployment, comprehensively deepening the classification of domestic waste among star-rated hotels and to add new reusable travel package sales service that will guide 
consumers to develop green living and consumption habits. In accordance with the principle of "reduction at source, classified recovery, resource utilization and harmless treatment", the special action plan will establish and improve a standardized, normalized and long-term working mechanism for the classification of domestic waste, to step up publicity and supervision of the disposable campaign in star hotels, comprehensively improve the level of garbage classification, and create a civilized, clean, healthy and environmentally friendly cultural tourism market environment (GMCRTTB, 2019).

This new regulation is not the first time that the Chinese government released the regulations to guide the development of the hotel industry about environmental protection. In order to emphasize environmental protection, the Classification and Accreditation for Star-rated Tourist Hotels eliminated toothbrushes, slippers and other toiletries of the mandatory requirements which took effect in January 1, 2011. Before this, other related regulations were issued across the country. In 2002, Shanghai first advocated the cancellation of "six small pieces" (toothbrush, hairbrush, bath brush, shoe brush, razor, and nail file) for hotels. In 2007, Beijing called for hotels to use large containers for shampoos. Changsha issued a "Notice on Prohibition of free Disposable in Hotels" in 2009. In 2015, Tourism accommodations and catering operators were ordered not to provide free disposables in Hangzhou. Four-star and Five-star hotels in Zhejiang Province no longer offered disposables in 2018. High-star hotels have a stronger commitment to environmental social responsibility. The social contract that highstar hotels need to maintain continuously is more extensive and complex, and their environmental behavior is easy to arouse people's attention, so high-star hotels pay more attention to their environmental behavior. Secondly, high-star hotels are well-known in the region (especially five-star hotels), which are easy to be concerned by the authorities and are often the focus of government environmental regulation (Zhang, 2013).

\section{Research Methodology}

The researcher used descriptive quantitative research to reveal the respondents' perception toward the implementation of the new regulation in the selected hotels in Guangzhou, China. In this respect, the researcher has conducted a survey to collect the data for the study so that the perception of the hotel employees on the reduction of the disposable toiletries can be examined. The survey was conducted among 108 employees working in the hotels. The demographic results have been outlined in the next results and analysis section.

\section{Results and Analysis}

\section{Profile of Respondents}

\section{Demographics of Hotel Employees}

Table 1 shows the summary of demographics of the hotel employees. It showed the frequency and percentage of the sex, age, and educational background of 108 employees. There were significantly more female respondents than male respondents. Among the respondents' age, the majority of employees are between the ages of 18 30, accounting for 87 percent of the total employee respondents, 
with a small number over 30 years old. The largest share of the educational background of the respondents is in tertiary education 85.19 percent, with a small number of primary education and secondary education.

Table 1: Demographics of Hotel Employees

\begin{tabular}{|l|l|l|}
\hline Particulars & $\mathbf{f}$ & \% \\
\hline Sex & & \\
\hline Male & 41 & 37.96 \\
\hline Female & 67 & 62.04 \\
\hline Total & $\mathbf{1 0 8}$ & $\mathbf{1 0 0}$ \\
\hline Age & & \\
\hline $18 \sim 30$ & 94 & 87.04 \\
\hline $31 \sim 55$ & 14 & 12.96 \\
\hline Total & $\mathbf{1 0 8}$ & $\mathbf{1 0 0}$ \\
\hline Educational Background & & \\
\hline Primary Education & 3 & 2.78 \\
\hline Secondary Education & 13 & 12.04 \\
\hline Tertiary Education & 92 & 85.19 \\
\hline Total & $\mathbf{1 0 8}$ & $\mathbf{1 0 0}$ \\
\hline
\end{tabular}

Indeed, as the hotel industry is a service industry, the gender composition of its employees will generally be more female than male, and the staff is mostly young people. Similarly, in Zhao (2015)'s study, most of the employees in his sample were between the ages of $18 \sim 29$. The proportion of young and middle-aged people is relatively large, which is related to the hotel is the characteristics of the service industry. Due to the increasing emphasis on national education in China, the implementation of the compulsory education, and the fact that the majority of respondents are young and middle-aged, the proportion of respondents with tertiary education is higher.

\section{Department and Designation of Hotel Employees}

Table 2 shows the summary of department and designation of 108 hotel employees. The respondents of the Housekeeping department are slightly more than the Front Office department. As for designation, among the employees, the staff is the most, the supervisors are the second, and the managers are the least.

Table 2: Department and Designation of Hotel Employees

\begin{tabular}{|c|c|c|}
\hline Employees & f & \% \\
\hline Department & & 55.56 \\
\hline Housekeeping & 60 & 44.44 \\
\hline Front Office & 48 & $\mathbf{1 0 0}$ \\
\hline Total & $\mathbf{1 0 8}$ & $\mathbf{7 3 . 1 5}$ \\
\hline Designation & 79 & 21.30 \\
\hline Staff & 23 & 5.56 \\
\hline Supervisor & 6 & $\mathbf{1 0 0}$ \\
\hline Manager & $\mathbf{1 0 8}$ & . \\
\hline Total & & House \\
\hline
\end{tabular}

Due to the different job responsibilities of the department, the Housekeeping department is responsible for the cleaning of the rooms, as well as the cleaning and laundry, therefore, the number of staff required is large. The Housekeeping department usually has one of the largest number of staff in the hotel, more than 
the Front Office department. The designation of the respondents basically conforms to the reality, most of them are staff, a few are supervisors, and very few are managers.

Hotel Employees' Perceptions about the Implementation of the Reduction of Disposable Toiletries

Table 3: Summary of Hotel Employees' Perceptions on the Regulation

\begin{tabular}{|c|c|c|c|}
\hline Particulars & $x$ & S.D. & V.I. \\
\hline 1. I know exactly what the regulation is. & 3.04 & .819 & Agree \\
\hline $\begin{array}{l}\text { 2. I am informed of how wasteful disposable } \\
\text { items. }\end{array}$ & 3.02 & .670 & Agree \\
\hline $\begin{array}{l}\text { 3. I have knowledge of the concept of the "Green } \\
\text { Hotel. }\end{array}$ & 3.05 & .754 & Agree \\
\hline Overall Awareness & 3.03 & .623 & Agree \\
\hline $\begin{array}{l}\text { 4. We were informed that the regulation would } \\
\text { take effect from September } 1,2019 \text {. }\end{array}$ & 3.00 & .723 & Agree \\
\hline $\begin{array}{l}\text { 5. The details of the regulation were discussed by } \\
\text { the manager. }\end{array}$ & 3.03 & .690 & Agree \\
\hline $\begin{array}{l}\text { 6. The manager gave us the training about how to } \\
\text { react when the guests were not satisfied with the } \\
\text { implementation of the regulation. }\end{array}$ & 2.97 & .729 & Agree \\
\hline Overall Readiness & 3.00 & .601 & Agree \\
\hline 7. The disposable items are hotel necessities. & 2.95 & .778 & Agree \\
\hline $\begin{array}{l}\text { 8. I prefer to work in an environmentally friendly } \\
\text { place. }\end{array}$ & 3.08 & .738 & Agree \\
\hline $\begin{array}{l}\text { 9. I support the implementation of environmental } \\
\text { protection and green practice. }\end{array}$ & 3.15 & .747 & Agree \\
\hline Overall Acceptance \& Attitude & 3.06 & .607 & Agree \\
\hline
\end{tabular}

Table 3 presents the summary of the hotel employees' perceptions on the implementation of the reduction of disposable toiletries. The results show an overall mean of 3.03 or .623 SD of their acceptance on the regulation which is verbally interpreted as "Agree"; for their readiness, the overall mean obtained was 3 or .601 SD verbally interpreted as "Agree"; and for their overall acceptance and attitude, the overall mean was 3.06 or .607 SD verbally interpreted as "Agree." This implies that employees have a higher recognition of the new regulation. With the highest score in the survey being " 4 ," the employees' summary overall rating of " 3 " on all three sub-items indicates that there is still room for improvement in all aspects of the implementation of the new regulation. 
Differences in the Perceptions of the Hotel Employees' About the Implementation of the Reduction of Disposable Toiletries

\section{When Grouped According to Sex}

Table 4 reveals that there was no significant difference on the perception of the employees about the implementation of the reduction of disposable toiletries as both male and female had same perception as seen on the items: Awareness $(P=0.300>0.050$, Readiness $(P=0.512>0.050$, and Acceptance and Attitude $(\mathrm{P}=0.352>0.05)$.

Table 4: Differences in Hotel Employees' Perception When Grouped According to Sex

\begin{tabular}{|l|l|l|l|l|l|l|}
\hline & Sex & $\mathbf{X}$ & SD & t-value & $\mathbf{p}$-value & Sig. \\
\hline \multirow{2}{*}{ Awareness } & Male & 3.11 & .669 & 1.043 & $\mathrm{P}=0.300>0.05$ & NS \\
\cline { 2 - 6 } & Female & 2.99 & .593 & & & \\
\hline \multirow{2}{*}{ Readiness } & Male & 3.05 & .613 & .658 & $\mathrm{P}=0.512>0.05$ & NS \\
\cline { 2 - 5 } & Female & 2.97 & .597 & & & \\
\hline \multirow{2}{*}{$\begin{array}{l}\text { Acceptance } \\
\text { and Attitude }\end{array}$} & Male & 2.99 & .648 & -.936 & $\mathrm{P}=0.352>0.05$ & $\mathrm{NS}$ \\
\cline { 2 - 4 } & Femal0 & .581 & & & \\
\hline
\end{tabular}

On the contrary, in the research of Cengiz (2018), he found that males were more sensitive to the environment than females in some terms, and that females were more sensitive to the environment than males in some terms. Similarly, female employees have a significantly higher green attitude in many parts than their male counterparts, like corporate social responsibility and green purchasing (Tsai, 2014). This implies that, in the minds of the employees, the implementation of the new regulation and the concept of environmental protection are not exactly the same and their gender did not affect their perception about the new regulation.

\section{When Grouped According to Age}

Table 5 presents "no significant differences" on the items pertaining to Awareness $(p=0.056>0.05)$ and Acceptance and attitude $(p=0.132>0.05)$ of the hotel employees, but there was a "significant difference" on the Readiness of hotel employees from the 18 to 30 age range about the implementation of the reduction of disposable toiletries.

Table 5: Differences in Hotel Employees' Perceptions When Grouped According to Age

\begin{tabular}{|l|l|l|l|l|l|l|}
\hline & Age & $\mathbf{X}$ & SD & t-value & $\mathbf{p}$-value & Sig. \\
\hline Awareness & $18-30$ & 3.08 & .605 & 1.928 & $\mathrm{p}=0.056>0.05$ & NS \\
\cline { 2 - 5 } & $31-55$ & 2.74 & .682 & & & \\
\hline \multirow{2}{*}{ Readiness } & $18-30$ & 3.06 & .596 & 2.610 & $\mathrm{p}=0.010<0.05$ & $\mathrm{~S}$ \\
\cline { 2 - 5 } & $31-55$ & 2.62 & .504 & & & \\
\hline \multirow{2}{*}{$\begin{array}{l}\text { Acceptance } \\
\text { and Attitude }\end{array}$} & $18-30$ & 3.10 & .594 & 1.519 & $\mathrm{p}=0.132>0.05$ & $\mathrm{NS}$ \\
\cline { 2 - 4 } & $31-55$ & 2.83 & .663 & & & \\
\hline
\end{tabular}

In the study of Cengiz (2018), he found that employees' age did not affect their environmental awareness, which is the same result as this study. As for readiness, young people are more adaptable, open to new things, and more likely to be prepared for the new regulations. Also, it seems easier for them to absorb 
the relevant training for the new regulation, thus the degree of readiness of employees aged 18-30 was higher than employees aged 31-55.

\section{When Grouped According to Department}

Table 6 reveals that there was "no significant difference" found on the perceptions of the employees between the housekeeping department and the front office department; they have the same perception.

Table 6: Differences in Hotel Employees' Perceptions When Grouped According to Department

\begin{tabular}{|l|l|l|l|l|l|l|}
\hline & Department & $\mathbf{X}$ & SD & t-value & p-value & Sig. \\
\hline Awareness & $\begin{array}{l}\text { Housekeepin } \\
\text { Readiness }\end{array}$ & 2.96 & .554 & -1.470 & $\begin{array}{l}\mathrm{P}=0.145>0.0 \\
5\end{array}$ & NS \\
& Front Office & 3.13 & .694 & & & \\
\cline { 2 - 5 } & $\begin{array}{l}\text { Housekeepin } \\
\mathrm{g}\end{array}$ & 2.91 & .502 & -1.674 & $\begin{array}{l}\mathrm{P}=0.098<0.0 \\
5\end{array}$ & $\mathrm{NS}$ \\
\cline { 2 - 4 } & Front Office & 3.11 & .696 & & & \\
\hline $\begin{array}{l}\text { Acceptanc } \\
\text { e and } \\
\text { attitude }\end{array}$ & $\begin{array}{l}\text { Housekeepin } \\
\mathrm{g}\end{array}$ & 3.01 & .600 & -1.077 & $\begin{array}{l}\mathrm{P}=0.284>0.0 \\
5\end{array}$ & $\mathrm{NS}$ \\
\cline { 2 - 4 } & Front Office & 3.13 & .614 & & 5 & \\
\hline
\end{tabular}

This implies that both employees from the housekeeping department and front office department are classified under Room Division. This means they are all part of the same department and receive the same training and management, so the departmental affiliation of employees does not affect their perception.

\section{When Grouped According to Educational Background}

There was "no significant difference" in the hotel employees' perceptions about the implementation of the reduction of disposable toiletries in terms of awareness, readiness, and acceptance and attitude when grouped according to educational background as seen on Table 7 .

Table 7: Differences in Hotel Employees' Perceptions When Grouped According to Educational Background

\begin{tabular}{|c|c|c|c|c|c|c|}
\hline & & $\mathbf{X}$ & SD & F-value & $p$-value & Sig. \\
\hline \multirow[t]{4}{*}{ Awareness } & Primary & 3.44 & .509 & \multirow[t]{4}{*}{2.507} & \multirow[t]{4}{*}{$P=0.086>0.05$} & \multirow[t]{4}{*}{ NS } \\
\hline & Secondary & 2.72 & .621 & & & \\
\hline & Tertiary & 3.07 & .616 & & & \\
\hline & Total & 3.03 & .623 & & & \\
\hline \multirow[t]{4}{*}{ Readiness } & Primary & 3.00 & 1.000 & \multirow[t]{4}{*}{.583} & \multirow[t]{4}{*}{$P=0.338>0.05$} & \multirow[t]{4}{*}{ NS } \\
\hline & Secondary & 2.77 & 1.095 & & & \\
\hline & Tertiary & 3.03 & .591 & & & \\
\hline & Total & 3.00 & .601 & & & \\
\hline \multirow{4}{*}{$\begin{array}{l}\text { Acceptance } \\
\text { and Attitude }\end{array}$} & Primary & 3.11 & .839 & \multirow[t]{4}{*}{.541} & \multirow[t]{4}{*}{$P=0.584>0.05$} & \multirow[t]{4}{*}{ NS } \\
\hline & Secondary & 2.90 & .658 & & & \\
\hline & Tertiary & 3.08 & .596 & & & \\
\hline & Total & 3.06 & .607 & & & \\
\hline
\end{tabular}

This implies that regardless of their educational background, they had the same perceptions about the implementation of the reduction of disposable toiletries. Cengiz 2018) noted that the hotel and restaurant employees' attitudes toward 
environmental awareness who were highly educated employees were more likely to be environmentally friendly.

\section{When Grouped According to Designation}

Table 8 shows that there was "no significant difference" found on the Readiness $(p=0.085>0.05)$ and Acceptance and Attitude $(p=0.101>0.05)$ of the employees when grouped according to designation. However, there was a "significant difference" found on Awareness as supervisors with a mean rating of 3.35 had a better awareness about the implementation of the reduction of disposable toiletries than staff. This result is supported by Zhang (2013), where he stated that the environmental awareness of hotel management is positively related to the environmental behavior of the hotel.

Table 8: Differences in Hotel Employees' Perceptions When Grouped According to Designation

\begin{tabular}{|c|c|c|c|c|c|c|c|}
\hline & & $\mathbf{X}$ & SD & $\begin{array}{l}\text { F- } \\
\text { value }\end{array}$ & $p$-value & Sig. & $\begin{array}{l}\text { Remarks } \\
\text { (Post Hoc) }\end{array}$ \\
\hline \multirow[t]{4}{*}{ Awareness } & Staff & 2.95 & .630 & \multirow[t]{3}{*}{2.507} & \multirow[t]{3}{*}{$p=0.023<0.05$} & \multirow[t]{3}{*}{$S$} & \multirow{6}{*}{$\begin{array}{l}\text { Staff vs } \\
\text { Supervisor }\end{array}$} \\
\hline & Supervisor & 3.35 & .527 & & & & \\
\hline & Manager & 3.00 & .558 & & & & \\
\hline & Total & 3.03 & .623 & \multirow[t]{3}{*}{2.526} & \multirow[t]{3}{*}{$p=0.085>0.05$} & \multirow[t]{3}{*}{ NS } & \\
\hline \multirow[t]{4}{*}{ Readiness } & Staff & 2.93 & .621 & & & & \\
\hline & Supervisor & 2.77 & .583 & & & & \\
\hline & Manager & 3.03 & .591 & \multirow[t]{6}{*}{2.348} & \multirow[t]{6}{*}{$p=0.101>0.05$} & \multirow[t]{6}{*}{ NS } & \\
\hline & Total & 3.00 & .601 & & & & \\
\hline \multirow{4}{*}{$\begin{array}{l}\text { Acceptance } \\
\text { and attitude }\end{array}$} & Staff & 3.03 & .630 & & & & \\
\hline & Supervisor & 3.26 & .482 & & & & \\
\hline & Manager & 2.72 & .574 & & & & \\
\hline & Total & 3.06 & .607 & & & & \\
\hline
\end{tabular}

Dang (2013) believes that both the department manager and supervisor mostly agree that it is important and urgent to be green in the hotel industry, but the frontline service personnel's green environmental protection consciousness also needs to be promoted. The environmental awareness of the hotel management affects its daily environmental behavior including the understanding of environmental policies and regulations. Managers and supervisors tend to be more holistic and more experienced than their staff, therefore, they are most likely to have a higher awareness about the new regulation.

Recommendations to Further Promote the Awareness, Readiness, and Acceptance and Attitude of the Employees

The new regulation orders hotels to not proactively provide six small pieces in the guest rooms. However, guests can still ask for six small pieces when they need them which means it is not a total ban. Obviously, given the actual demand and consumption habits, from the restrictions to the abolition of the need for a gradual process, so that hotels and guests can slowly adapt. An article from the Yangcheng Evening News (2019b) which noted that hotels had put up notices at their front desks and in the rooms to remind the guests that the hotel were no longer proactively providing the usual six small pieces starting September 1, 2019. 
However, should guests still need them, these could still be picked up at the front desk; star-rated hotels and some non-star-rated hotels in Guangzhou were reminded under the "booking notes" column of CTRIP and Fliggy that hotels must ensure that guests would be informed of this arrangement when they book on the platform, and prepare supplies in advance. Nevertheless, one hotel attempted to make a travel kit out of the six small pieces that were once offered for free had now put them on sale in the rooms. Liu (2011) suggests that hotels should use various flexible means such as brochures, enthusiastic explanations from the service staff, and compensation for the value of the benefits to reassure customers, and through high-quality green ecological products and ecological services to enhance the hotel's high added value. While the hotel has taken steps to address the new regulation, more needs to be done to gradually change the perception of employees and guests. Noting all these, recommendations given below are to make hotels and guests more receptive to the new regulation and push ahead with environmentally friendly measures such as eliminating the use of six small pieces eventually.

\section{Recommendations for Hotels}

Discuss the details of the new regulation to the employees and train them on how to deal with the possible reactions of the guests. In order to do that, the hotels need to conduct a re-orientation on regulations with all hotel employees; 2) Set up training courses to cultivate employees' awareness of environmental protection and green practice. In order to do that, the hotels need to hire experts to train employees on environmental protection, green hotel and other related knowledge. Include the promotion of awareness, readiness and acceptance of six small pieces in the regular training programs of the hotel; 3) In the room reservation system, add options "whether or not to need six small pieces", and specific to each, so that guests can choose freely. When guests check in, the front desk employees should remind the guests about the regulation again and ask if the guests need six small pieces. In order to do that, the hotels need to adjust the reservation system settings to meet the new changes.

\section{Research Limitation and Future Direction}

This study focused on determining the perceptions of the hotel employees on the new regulation of disposable toiletries among selected five-star hotels in Guangzhou, China. The respondents were selected from employees who were hired in the housekeeping and front office departments before September 1, 2019. It only covered the respondents' profile, in terms of sex, age, educational background, department and designation. The disposable items are those in the regulation which provide in the hotel guest room, namely toothbrush, hairbrush, bath brush, shoe brush, razor, and nail file.

To increase the sample size in more cities where this regulation was applied like Shanghai, Hainan, Beijing, and Chengdu, collecting more data to come to a more accurate conclusion and recommendation; To include other profile information about the respondents, such as their marital status and the number of years employed in the company of the employees, to gain a comprehensive understanding of the factors affecting their perceptions. 


\section{Conclusions}

Overall, paper examined whether hotel employees' profile can influence their perceptions on the implementation of the reduced supply of toiletries and disposables among selected five-star hotels in Guangzhou, China. With the new regulations issued by the Guangzhou government, moreover, the concept of a green hotel, has led the researcher to investigate a range of issues as a result of these new regulations and related environmental awareness among hotel employees. Employing descriptive-quantitative research using questionnaires answered by the 108 hotel employees, the study found that the profile of respondents did affect their perceptions. The researcher aimed to improve the attitude, awareness and readiness of the hotel employees on the reduction of disposable toiletries and gave suggestions on how to promote the green hotel in Guangzhou.

\section{Acknowledgement}

For the final development of this study, the researcher wishes to extend her gratitude to Dr. Amelia S. Butial, thesis adviser and Director, Career Development Academy, St. Paul University Manila, for her patient guidance and warm support to the researcher to accomplish this work.

\section{References}

Chen, H. X. (2019). In Search of Patterns among Travellers' Hotel Ratings under Place-related Context and Travellers' Profile, available at: https://kns.cnki.net/kns8/defaultresult/index (accessed 28 July 2020).

Chen, Z. D. (2019). Research on the development stages and existing characteristics of the hotel industry in China, available at: https://kns.cnki.net/kns8/defaultresult/index (accessed 28 July 2020).

China Circular Economy Development Report (2017). China Association of Circular Economy. Retrieved from http://www.chinacace.org/patents/cycle_economy_report.

Dang, X. W. (2013). Study on Environmental Protection Behavior of Green Hotel in Beijing, available at: https://kns.cnki.net/kns8/defaultresult/index(accessed 28 July 2020).

Hebei News (2019). "The Abolition of Six Small Pieces Brings Great Benefits", available at: http://hebei.hebnews.cn/201908/29/content 7456420.htm.

King, Y., Wan, P., Hup, S., Chan, J., Lan, H. \& Huang, W., (2017), "Environmental awareness, initiatives and performance in the hotel industry of Macau", Tourism Review, Vol. 72. http://dx.doi.org/10.1108/TR-06-2016-0016. 
Li, J. (2013). Study on the Reform of Disposable Items A Customer Cognition Domestic Hotel Rooms, available at: https://kns.cnki.net/kns8/defaultresult/index (accessed 28 July 2020).

Li, X. Y. (2007). Research on Green Development in China, available at: https://kns.cnki.net/kns8/defaultresult/index(accessed 28 July 2020).

List of Five-star Hotel (2019). China Tourist Hotel Association, available at: http://www.ctha.com.cn/detail-23-94-2918.html

Liu, H. D. (2011). The Study of Customer Support Level about Ecohotel Energy-saving Emission Reduction, available at: https://kns.cnki.net/kns8/defaultresult/index (accessed 28 July 2020).

Liu, Y. L. (2008). The Research of Standard and Problem in Implementation of Green Hotel and Solution Strategy, available at: https://kns.cnki.net/kns8/defaultresult/index (accessed 28 July 2020).

Lu, L. (2015). A Research on the Influence of Hotel Environmental Behavior on Corporate Performance, available at: https://kns.cnki.net/kns8/defaultresult/index (accessed 28 July 2020).

National Standard of Green Hotel (2015). China Hospitality Association, available at: http://www.chinahotel.org.cn

Statistical Bulletin of National Star-rated Hotels in the Fourth Quarter of 2018 (2019). Ministry of Culture and Tourism of the People's Republic of China, available at: http://zwgk.mct.gov.cn/zfxxgkml/tjxx/202012/t20201204_906483. html (accessed 30 July 2019).

The Guangzhou Municipal Culture, Radio, Television and Tourism Bureau Organized a Meeting to Promote the Overall Development of Star Hotels and Reduce the Deployment of Disposable (2019). Guangzhou Municipal Culture, Radio, Television and Tourism Bureau, available at: http://wglj.gz.gov.cn/zwpd/xxgk/gzdt/content/post_3239284

Wang, J. Z. (2014). "International Hotel Industry Development". In Hotel management pp. 216. Northeastern University Press.

Wang, Y. Z. (2013). Research on Competitiveness of China's Sport Tourism Industry, available at: https://kns.cnki.net/kns8/defaultresult/index (accessed 28 July 2020). 
Yangcheng Evening News (2019a). "Star hotels do not provide six small pieces?" available at: http://ep.ycwb.com/epaper/ycwb/ html/2019-08/29/content_35751_180687.htm

Yangcheng Evening News (2019b). "Guangzhou Hotels No Longer Provide Six Small Pieces", available at: http://news.ycwb.com/2019-09/06/content_30332957.htm

Yang, W. (2013). Study of the Implementation of Green tourism in the Perspective of Low-Carbon Economy -Take Implementation of Green Tourism in Shanxi Jincheng City as An Example, available at: https://kns.cnki.net/kns8/defaultresult/index (accessed 28 July 2020).

Yucedag, C., Kaya, L.G., \& Cetin, M. (2018). Identifying and Assessing Environmental Awareness of Hotel and Restaurant Employees' Attitudes in the Amasra District of Bartin. Environ Monit Assess 190:60. https://doi.org/10.1007/s10661-017-6456-7

Zhang, H. (2013). A research on Hotel Environmental Behavior and ITS Internal Driving Mechanism, available at: https://kns.cnki.net/kns8/defaultresult/index (accessed 28 July 2020).

Zhang, L., Wu, J., Liu, H. Y., \& Zhang, X. L. (2017). The Value of Going Green in the Hotel Industry: Evidence from Beijing. Real Estate Economics. 2017 V: pp. 1-26. DOI: 10.1111/15406229.12225

Zhao, K. F. (2015). Research on the Influence of Energy Conservation and Emissions Reduction to Hotel Performance, available at: https://kns.cnki.net/kns8/defaultresult/index (accessed 28 July 2020).

Zheng, X. L. (2012). Six little pieces has become a Rat? Environment, Vol. 10, 10-11.

Zhou, Y. (2015). "Legislate before Cancellation of Hotel Disposable", 11, August. Guangzhou Daily, available at: http://opinion.people.com.cn/n/2015/0811/c15930127440344.ht $\mathrm{ml}$ 